\title{
Diabetes Provides an Unfavorable Environment for Muscle Mass and Function after Muscle Injury in Mice
}

\author{
A. Vignaud ${ }^{\text {a }} \quad$ F. Ramond ${ }^{d} \quad$ C. Hourdé ${ }^{c} \quad$ A. Keller ${ }^{c} \quad$ G. Butler-Browne ${ }^{a}$ \\ A. Ferry ${ }^{a, b}$ \\ aINSERM U787 and Université Pierre et Marie Curie-Paris 6, and b Université Paris Descartes, Paris; \\ ${ }^{c}$ CNRS UMR 7149, Créteil; dENS Lyon CNRS UMR 5239, IFR128, Lyon, France
}

\section{Key Words}

Atrogenes · Atrophy $\cdot$ Diabetes $\cdot$ Injury $\cdot$ Muscle function • Muscle recovery

\begin{abstract}
It is of common knowledge that diabetes decreases skeletal muscle contractility and induces atrophy. However, how hyperglycemia and insulin deficiency modify muscle mass and neuromuscular recovery after muscle injury is not well known. We have analyzed two models of diabetes: streptozotocin (STZ)-treated Swiss mice and Akita mice that spontaneously develop diabetes. A fast muscle, the tibialis anterior, was injured following injection of a myotoxic agent (cardiotoxin). Neuromuscular function was evaluated by examining in situ isometric contractile properties of regenerating muscles in response to nerve stimulation 14, 28 and 56 days after myotoxic injury. We found that STZ-induced diabetes reduces muscle weight and absolute maximal tetanic force in both regenerating and uninjured muscles $(p=$ $0.0001)$. Moreover, it increases specific maximal tetanic force and tetanic fusion in regenerating and uninjured muscles $(p=0.04)$. In the Akita mice, diabetes decreases muscle weight and absolute maximal tetanic force, and increases tetanic fusion in both regenerating and uninjured muscles ( $p \leq 0.003$ ). Interestingly, STZ-induced diabetes exerts more
\end{abstract}

marked effects than diabetes of genetic origin, in particular on muscle weight. This reduction in muscle mass was not due to an increased expression of the atrogenes MuRF1 and atrogin-1 during STZ-induced diabetes. The present study in mice demonstrates that both models of diabetes impair regenerating muscles as well as uninjured muscles. Regenerating fast muscles are weaker, lighter and slower in diabetic compared with nondiabetic mice.

Copyright $\odot 2007$ S. Karger AG, Base

\section{Introduction}

Diabetes is of great public health concern. Rodent models of diabetes are widely used to study its pathophysiology as well as to develop therapeutic strategies. Several investigations have been concerned with the effect of diabetes on rodent hindlimb skeletal muscles. They have shown that diabetes impairs muscle contractility and induces muscle atrophy [1-4]. Different hypotheses have been formulated to explain the alterations in muscle function in the diabetic state (see Discussion). Decreased diabetic muscle mass mostly results from the dramatic activation of proteolysis via the ATP-dependent ubiquitin-proteasome pathway, at least during the 1st week following insulin deficiency induction [5]. This ac-

\section{KARGER}

Fax +4161306 1234

E-Mail karger@karger.ch

www.karger.com (c) 2007 S. Karger AG, Basel

1015-2008/07/0745-0291\$23.50/0

Accessible online at:

www.karger.com/pat
Arnaud Ferry

UMR-787, Faculté de Médecine, Université Pierre et Marie Curie

105 Boulevard de l'Hôpital

FR-75634 Paris Cedex 13 (France)

Tel. +33 140779 691, Fax +33 153600 802, E-Mail arnaud.ferry@univ-paris5.fr 
tivation is associated with an increased expression of several components of this system, like ubiquitin and proteasome subunits coding genes. Deficiency in insulin signaling accompanies diabetes and also impairs the activation of the PI3-kinase/Akt pathway, thus allowing entry of FoxO family transcription factors into the myonuclei and the subsequent gene activation of Atrogin-1 and $M u R F 1$ [6]. These genes are termed atrogenes because they both encode some skeletal muscle atrophyspecific E3 ubiquitin ligase proteins responsible for the muscle-wasting process.

Although muscles have a remarkable ability to alter their phenotype in response to increased muscular activity, damage is known to be generated by excessive muscular exercises, as well as trauma, neuromuscular diseases and myotoxic agents $[7,8]$. However, very little information is available concerning the rate and extent of muscle repair after injury in the diabetic environment $[9$, 10]. To our knowledge, no study has examined the effect of diabetes on the restoration of neuromuscular function after muscle injury. It is important to note that diabetes does not only affect muscle fibers but also nerve branches and blood vessels, all elements known to play a major role in muscle repair $[7,11]$. For instance, diabetes induces pathological changes in motoneurons and in neuromuscular junctions $[2,12]$. It would therefore be pertinent to study diabetic muscle function in situ.

The aim of the present experiments in mice was to assess the outcome of diabetes on muscle mass and on the recovery of neuromuscular function following myotoxic injury that destroys muscle fibers but leaves intact satellite cells, blood supply and innervation. We wanted to test the hypothesis that diabetes would reduce muscle mass and neuromuscular recovery after myotoxic injury. This hypothesis is based on reports that tissue healing, and muscle regeneration after transplantation, is clearly impaired in a diabetic environment $[9,10,13]$. In the present study, two procedures were used to generate diabetes. Diabetes was induced by streptozotocin (STZ, a pancreatic $\beta$-cell toxin) administration [14]. We also used Akita mice that spontaneously develop diabetes [15], a genetic model of diabetes without the potential toxic side effects of chemical administration. Muscle recovery was observed following the extensive muscle necrosis created by injecting the myotoxic agent, cardiotoxin, into muscles of diabetic and nondiabetic mice. Neuromuscular function was evaluated in situ by examining force production in response to nerve stimulation. Our findings demonstrate that diabetes has detrimental effects on both muscle mass and function after myotoxic injury.

\section{Materials and Methods}

\section{Animals}

All procedures involving young adult rodents were performed in accordance with national and European legislations, using young adult rodents. The study was approved by the Ethical Committee for Animal Experimentation at the University Paris 6. Two types of diabetes were studied. First, male Swiss mice (15-20 g) were purchased from Janvier (France). They received a single intraperitoneal injection of STZ (Sigma), $200 \mathrm{mg} / \mathrm{kg}$ at 2-3 months of age. STZ was dissolved in sodium citrate buffer ( $\mathrm{pH} 4.5)$. These mice were used 4 weeks after STZ treatment. Second, Akita mice [15] were kindly provided by Dr. M. Levi-Strauss (INSERM U580, Paris, France). Original founders were obtained from Charles River (France). Male diabetic Akita mice (heterozygous, C57BL/6 genetic background) were mated to nondiabetic female C57BL/6 mice. Only male mice progeny at 3-4 months of age were studied. Urinary glucose concentration was assessed with reagent strips (Bayer). Mice with a urine glucose $>2,000 \mathrm{mg} / \mathrm{dl}$ were presumed to be diabetic. Blood glucose concentrations were measured with a glucometer to confirm the diabetic status of STZ-treated Swiss mice and Akita mice ( $>16 \mathrm{~mm})$. Following the administration of STZ, almost all Swiss mice developed diabetes in contrast to only about half of the Akita mice.

\section{Myotoxic Treatment}

Extensive muscle necrosis was created by injecting a myotoxic agent into diabetic and nondiabetic mice $[8,16]$. Cardiotoxin exhibits protein kinase $\mathrm{C}$ activity and is a pore-forming agent that causes the degradation of the plasma membrane [8]. In the present study, we verified that hematoxylin-stained transverse sections of myotoxic-treated muscles exhibited centronucleated muscle fibers (regenerating muscle fibers) that filled $>80-100 \%$ of the muscle cross-section area 56 days after myotoxic injury, confirming that our myotoxic treatment resulted in an almost total destruction of tibialis anterior (TA) muscles in every mouse, as previously observed $[17,18]$. Animals were anesthetized with pentobarbital $(60 \mathrm{mg} / \mathrm{kg})$. Surgery was performed on right legs in order to inject myotoxic agent into hindlimb muscles. Cardiotoxin (C-3987; Sigma-Aldrich, $10 \mu \mathrm{M}$ in $70 \mu \mathrm{l}$ normal saline) was injected into right TA (fast-twitch) muscles. A needle connected to a microsyringe was inserted near the distal tendon, pushed up to the proximal tendon, and the myotoxic solution was injected into the muscle, the needle being pulled up in order to deliver the solution along the entire length of the muscle. Contralateral (left) legs were left intact and were used as normal (uninjured) muscles. Contralateral muscles are apparently a good control to injured muscles since no differences were observed between the right and left normal muscles [19]. The mobility of the animals had generally returned to normal a few days after surgery.

\section{Neuromuscular Function}

The isometric contractile properties of left and right TA muscles were studied in situ 14, 28 and 56 days after myotoxic treatment. Measurements were performed according to previously detailed methods [17]. During experiments, animals were anesthetized with pentobarbital $(60 \mathrm{mg} / \mathrm{kg})$. Supplemental doses of anesthetic were given as required to maintain deep anesthesia. All isometric contraction measurements were made at an initial muscle length of $\mathrm{L}_{0}$ (length at which maximal tension was obtained 
during the twitch). Briefly, the knee and the foot were fixed using clamps. The muscle distal tendon was attached to an isometric transducer (Harvard Bioscience, Les Ulis, France) using a silk ligature. Great care was taken to ensure that blood and nerve supply remained intact during surgery. All data provided by the isometric transducer were recorded and analyzed on a microcomputer using the PowerLab system (4SP; ADInstruments) and software (Chart 4; ADInstruments). Body temperature was maintained at $37^{\circ} \mathrm{C}$ using radiant heat. In order to maintain the muscle temperature as near as possible to $37^{\circ} \mathrm{C}$, drops of mineral oil at $37^{\circ} \mathrm{C}$ were regularly applied during the functional measurements. The sciatic nerve (proximally crushed) was stimulated by bipolar silver electrodes using a supramaximal square wave pulse of $0.1 \mathrm{~ms}$ duration. Following single or repetitive electrical stimulation (at pulse frequencies of $6.25,12.5,25,50,100$ and $143 \mathrm{~Hz}$; train duration of $500 \mathrm{~ms}$ ), muscle force responses were successively recorded. At least $1 \mathrm{~min}$ was allowed between stimulations. The following parameters were studied: maximal tetanic force $\left(\mathrm{P}_{0}\right)$ and tetanic fusion. Tetanic fusion was calculated as the $\mathrm{a} / \mathrm{b}$ ratio, where $\mathrm{a}$ and $\mathrm{b}$ were the minimal (relaxation) and maximal (contraction) tensions of the third twitch of the tetanus (pulse frequency of 12.5 $\mathrm{Hz})$, respectively. Specific maximal tetanic force $\left(\mathrm{P}_{0} / \mathrm{m}\right)$ was also calculated $\left[\mathrm{P}_{0} / \mathrm{m}=\mathrm{P}_{0}(\mathrm{~g}) /\right.$ muscle mass $\left.(\mathrm{g})\right]$. Fatigue resistance was then determined after a 5-min rest period. Muscles were stimulated for $45 \mathrm{~s}$ at $50 \mathrm{~Hz}$, the times corresponding to a $20 \%$ decrease in tension were noted.

After contractile measurements, animals were killed with an overdose of pentobarbital. Muscles were then weighed, frozen in liquid nitrogen and stored at $-80^{\circ} \mathrm{C}$.

\section{Quantitative RT-PCR Analysis of Atrogenes}

Total RNA was extracted from TA muscles of STZ-treated, Akita and corresponding control mice using the Nucleospin RNA II kit (Macherey-Nagel, France) according to the manufacturer's instruction. First-strand cDNA was synthesized from $1 \mu \mathrm{g}$ of total RNA using the Superscript II reverse transcriptase as described by the manufacturer (Life-Technologies, France) with random hexameric primers. For the quantitative PCR, primer sequences were chosen using the primer 3 input software (www-genome. wi.mit.edu), with Tm fixed at $60^{\circ} \mathrm{C}$ and amplicon length between 100 and 150 bp. Primer sequences were as follows: $\beta$-actin: forward 5'-CCCTGTATGCCTCTGGTCG-3', reverse $5^{\prime}$-ATGGCGTGAGGGAGAGCAT-3'; mHDAC6: forward: 5'-AAGTGGAAGAAGCCGTGCTA- ${ }^{\prime}$, reverse $5^{\prime}$-CTCCAGGTGACACATGATGC-3'; mfoxo3a: forward 5'-AGCCGTGTACTGTGGAGCTT-3', reverse 5'-TCTTGGCGGTATATGGGAAG-3'; $m M A F b x$ : forward 5'-CAGACCTGCATGTGCTCAGT-3', reverse 5'-CCAGGAGAGAATGTGGCAGT-3'. m CyclophilinB: forward 5'-GATGGCACAGGAGGAAAGAG; reverse 5'-AACTTTGCCCGAAAACCACAT-3'; mMURF1: forward 5'-ACCTGCTGGTGGAAAACATC-3'; reverse 5'-AGGAGCAAGTAGGCACCTCA-3'.

Real-time quantitative RT-PCR was performed according to the manufacturer's instructions with the Roche SYBRGreen Master Plus DNA detection kit in a Light-Cycler 1.5 (Roche Molecular Diagnostic). Results were normalized to Cyclophilin B expression.

\section{Statistical Analysis}

Data were analyzed using Statistica 5.5 software (StatSoft, Paris, France). Groups of muscles from STZ-treated Swiss or Aki- ta mice were statistically compared using three-way analysis of variance (diabetes $\times$ time $\times$ myotoxic injury) with repeated measures for myotoxic injury. If necessary, subsequent contrast analysis was also performed in order to study significant interaction between factors. The effects of STZ-induced diabetes and diabetes in Akita mice were statistically compared using one-way analysis of variance. The significance level was set at $p<0.05$. When variables were not normally distributed and/or equality of variance were not obtained (tetanic fusion in STZ-treated mice and Akita mice, fatigue resistance in Akita mice), comparisons were made on transformed data (rank number). Values are means \pm SEM. Only significant differences between diabetic and nondiabetic muscles are discussed.

\section{Results}

\section{Diabetes Induced by STZ in Swiss Mice}

Type 1 diabetes was generated by STZ administration in Swiss mice, and 4 weeks later, the regeneration was induced in right TA muscles by injection of a myotoxic agent. Injured and normal (uninjured, left) TA muscles were studied at different times after myotoxic treatment.

The three-way analysis of variance (diabetes $\times$ time $\times$ myotoxic injury) shows the main significant effects of diabetes on all studied muscle parameters (muscle weight, fatigue resistance, maximal tetanic force, specific maximal tetanic force and tetanic fusion). Diabetes induced by STZadministration decreased muscle weights $(\mathrm{p}=0.0001$, fig. 1), fatigue resistance ( $\mathrm{p}=0.02$, fig. 2 ) and maximal tetanic force ( $p=0.0001$, fig. 3 ). Moreover, diabetes increased specific maximal tetanic force $(p=0.04$, fig. 4$)$ and tetanic fusion ( $\mathrm{p}=0.04$, fig. 5 ).

This analysis also revealed two interactions between diabetes and one of two other factors (times or myotoxic injury). These two interactions were: (a) diabetes and myotoxic injury interaction $(\mathrm{p}=0.04)$, with myotoxictreated muscles being lighter than uninjured muscle in diabetic mice ( $p=0.007$, fig. 1 ), and (b) diabetes and time interaction $(\mathrm{p}=0.02)$, with diabetic mice exhibiting reduced fatigue resistance compared with nondiabetic mice on day 14 ( $\mathrm{p}=0.001$, fig. 2$)$.

\section{Diabetes in Akita Mice}

Right TA muscles of Akita mice that spontaneously develop diabetes were treated with myotoxin and studied at different times of recovery.

Three-way analysis of variance shows that there were main effects of diabetes on muscle weight, maximal tetanic force and tetanic fusion in Akita mice. Diabetes in Akita mice decreased muscle weights $(p=0.0001$, fig. 6$)$ 


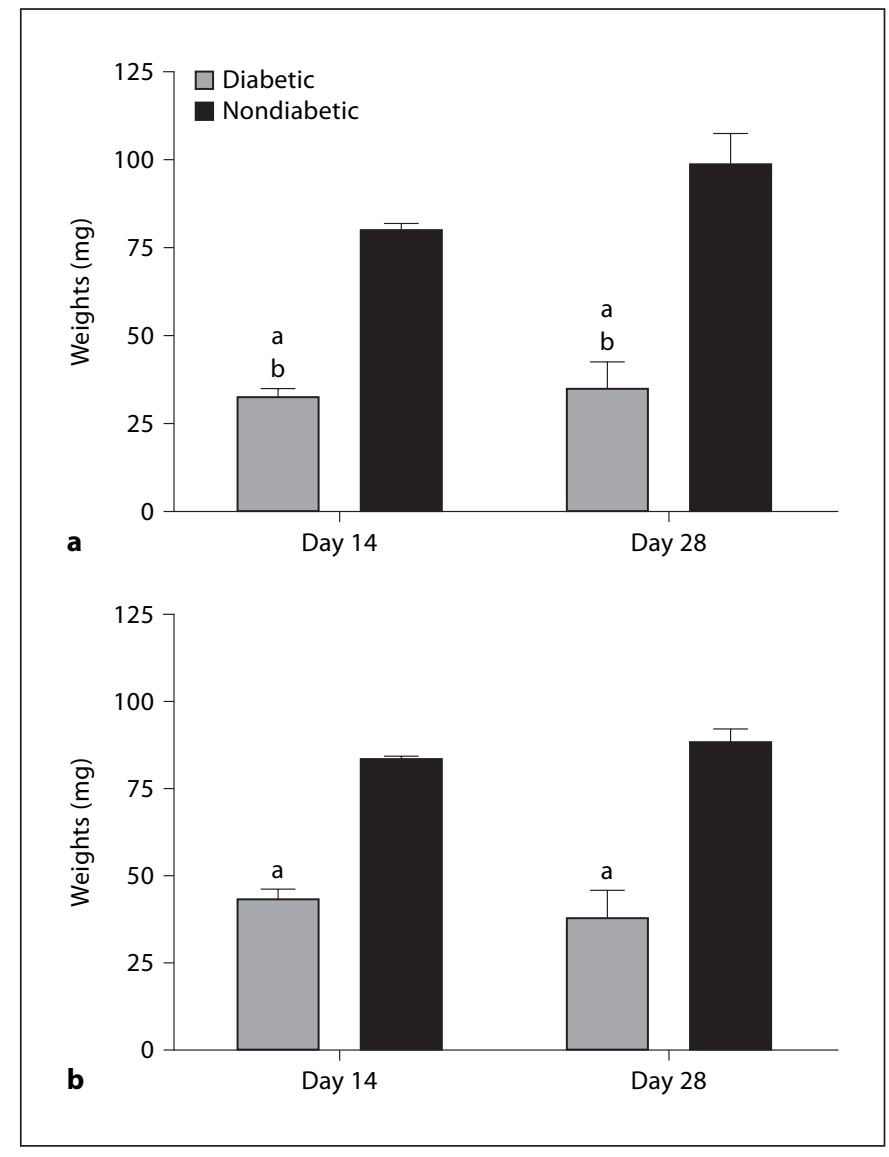

Fig. 1. Weights of TA muscles after myotoxic injury in STZ-treated Swiss mice (means \pm SEM; $n=4-6$ /group). Main significant effects of diabetes $(38.3 \pm 3.9$ in diabetic vs. $85.4 \pm 6.7 \mathrm{mg}$ in nondiabetic mice; $\left.{ }^{a} \mathrm{p}=0.0001\right)$, and diabetes-myotoxic injury interaction (diabetic mice: $33.9 \pm 3.9$ in myotoxic-treated muscles vs. $42.6 \pm 4.2 \mathrm{mg}$ in myotoxic-untreated muscles; ${ }^{\mathrm{b}} \mathrm{p}=0.007$ ) are shown in injured (a) and uninjured mice (b).

and maximal tetanic force $(\mathrm{p}=0.0008$, fig. 7$)$. Moreover, diabetes increased tetanic fusion ( $p=0.003$, fig. 8 ).

This analysis also revealed an interaction between diabetes and either of the two other factors (time or myotoxic injury). There was an interaction between diabetes and myotoxic injury $(\mathrm{p}=0.046)$, with muscle weights being increased by myotoxic injury in nondiabetic mice $(\mathrm{p}=0.008$, fig. 6$)$.

\section{Comparison between STZ-Treated Mice and Akita \\ Mice}

Table 1 shows that the statistically significant effects of diabetes on muscle weight ( $\mathrm{p}=0.000001)$, tetanic fusion $(\mathrm{p}=0.024)$ and maximal tetanic force $(\mathrm{p}=0.000054)$ were greater in STZ-treated mice compared with Akita mice.
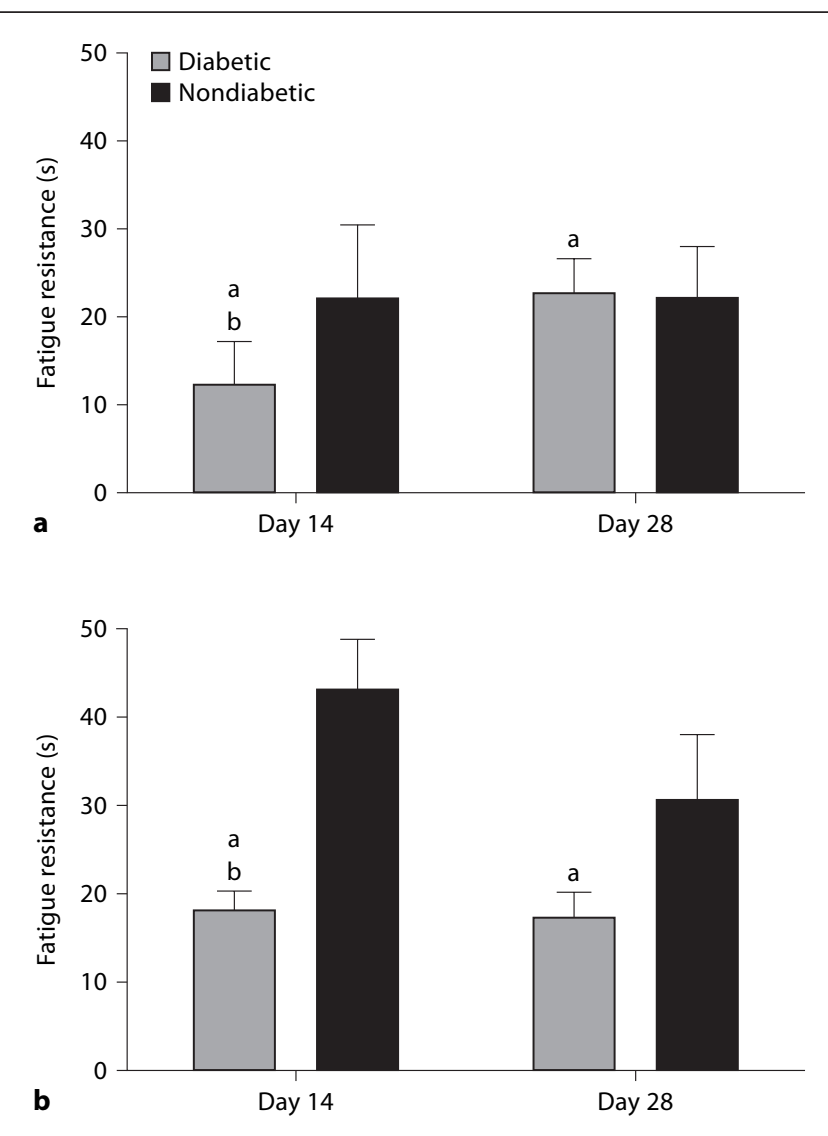

Fig. 2. Fatigue resistance of TA muscles after myotoxic injury in STZ-treated Swiss mice (means \pm SEM; $n=4-6$ /group). Main significant effects of diabetes $(17.5 \pm 2.8$ in diabetic vs. $32.4 \pm$ $5.1 \mathrm{~s}$ in nondiabetic mice; ${ }^{\mathrm{a}} \mathrm{p}=0.02$ ) and diabetes-time interaction (by day 14: $17.5 \pm 2.8$ in diabetic vs. $32.4 \pm 5.1 \mathrm{~s}$ in nondiabetic mice; ${ }^{b} \mathrm{p}=0.001$ ) are shown in injured (a) and uninjured mice (b).

To investigate the possibility that the expression of atrogenes could explain the greater muscle atrophy in STZ-treated mice, transcript levels of atrogin-1, MuRF1 and FoxO3A were quantified by quantitative RT-PCR analysis 2 months after muscle injury and 3 months after the onset of diabetes. Despite the differences in measured muscle mass between STZ-treated and Akita diabetic mice, no significant change in atrogene expression was observed. Moreover, atrogene transcript levels in these two diabetic states were the same as in nondiabetic muscles, suggesting that the activation of the FoxO/Atrogin1/MuRF1 pathway did not persist after the first few weeks following the onset of insulin resistance, but rather returned to a basal level (fig. 9). 


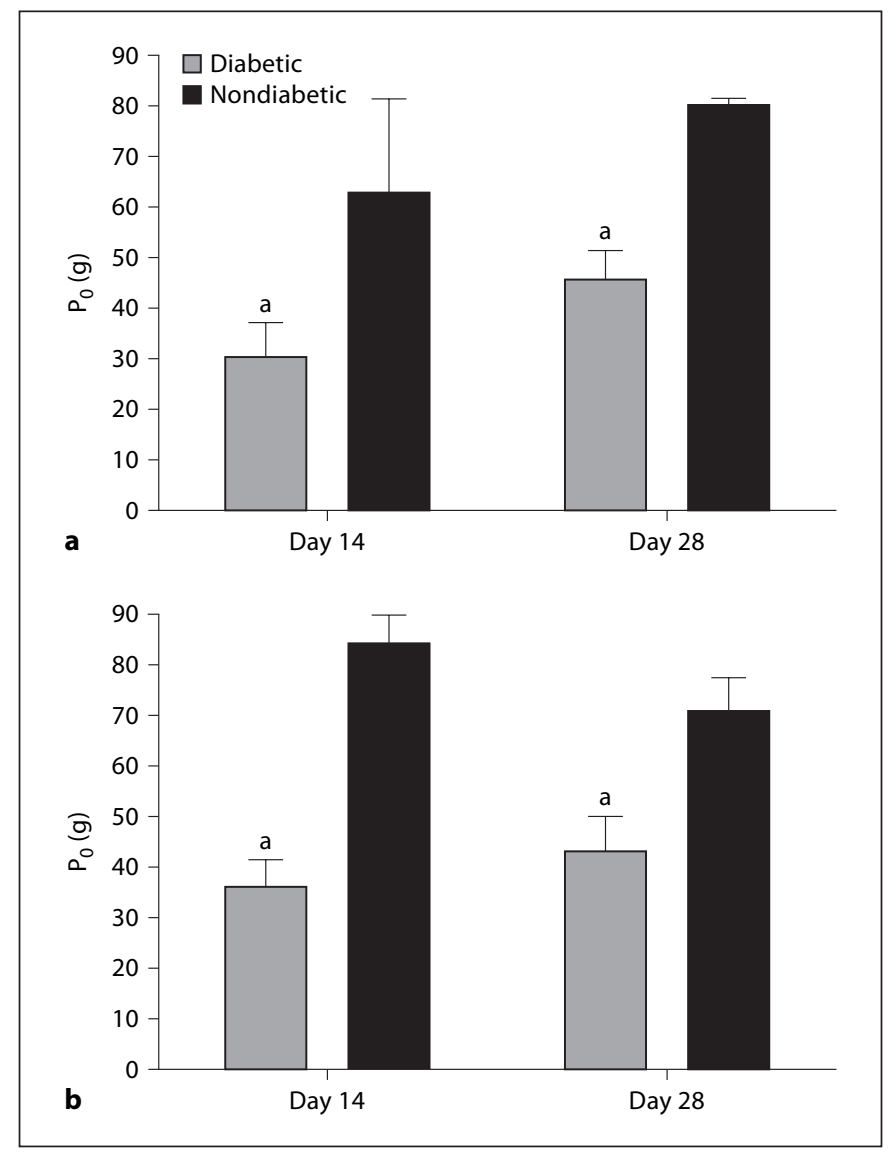

Fig. 3. Maximal tetanic force $\left(\mathrm{P}_{0}\right)$ of TA muscles after myotoxic injury in STZ-treated Swiss mice (means \pm SEM; $\mathrm{n}=4$-6/group). Main significant effects of diabetes $(39.5 \pm 4.6$ in diabetic vs. 74.7 $\pm 3.7 \mathrm{~g}$ in nondiabetic mice; ${ }^{\mathrm{a}} \mathrm{p}=0.0001$ ) are shown in injured (a) and uninjured mice (b).

\section{Discussion}

The aim of this study was to examine the effect of type 1 diabetes on the restoration of neuromuscular function following myotoxic injury in two diabetic mouse models. Despite the fact that it is already known that diabetes affects normal (uninjured) skeletal muscle and innervation, little information is available concerning neuromuscular recovery following injury in the diabetic environment. In the present study, our analyses of the in situ contractile properties in response to nerve stimulation indicate that diabetes, as well as having an effect on normal (uninjured) muscle maintenance, affects regenerating (injured) muscles in a detrimental way.



Fig. 4. Specific maximal tetanic force $\left(\mathrm{P}_{0} / \mathrm{m}\right)$ of TA muscles after myotoxic injury in STZ-treated Swiss mice (means \pm SEM; $\mathrm{n}=$ 4-6/group). Main significant effects of diabetes (1,094.5 \pm 128.7 in diabetic vs. $857.7 \pm 51.8 \mathrm{~g} / \mathrm{g}$ in nondiabetic mice; $\left.{ }^{\mathrm{a}} \mathrm{p}=0.04\right)$ are shown in injured (a) and uninjured mice (b). 


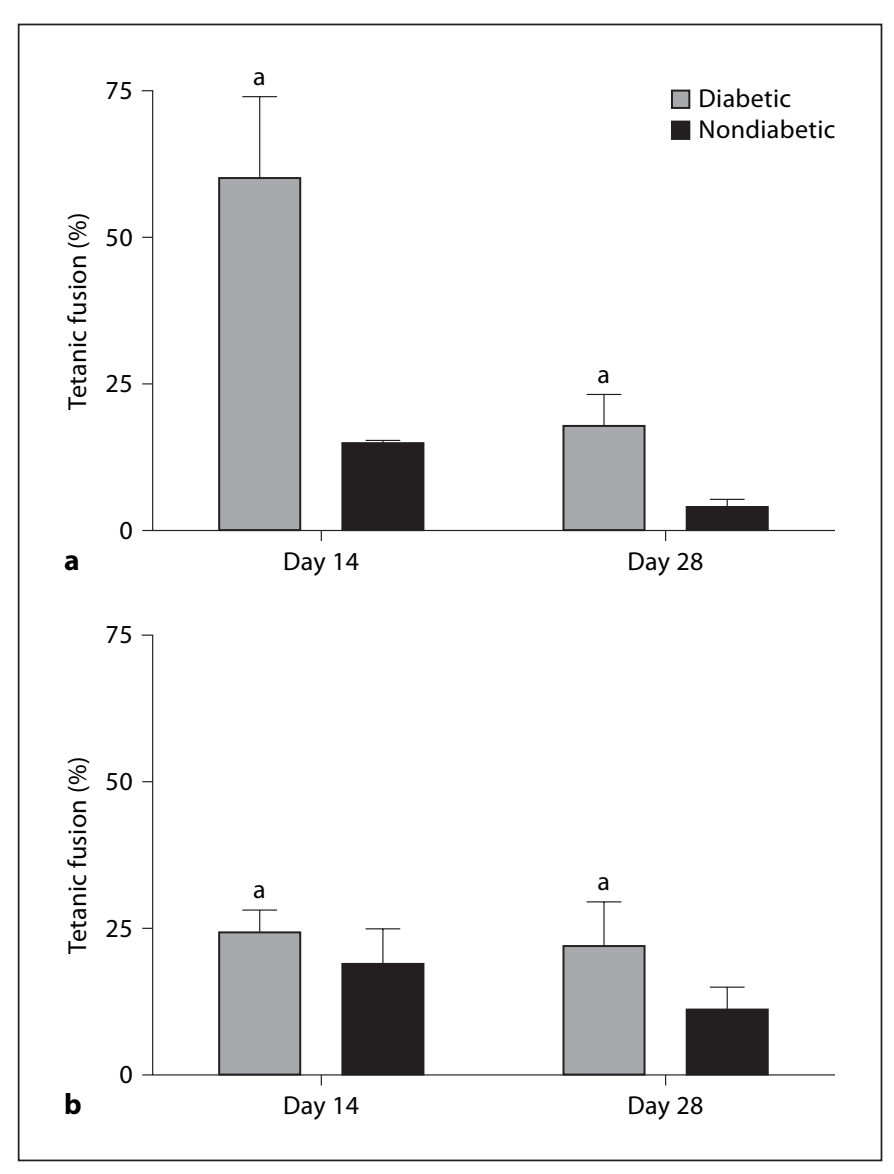

Fig. 5. Tetanic fusion of TA muscles after myotoxic injury in STZtreated Swiss mice (means \pm SEM; $n=4-6$ /group). Main significant effects of diabetes $(27.5 \pm 7.8$ in diabetic vs. $11.8 \pm 2.3 \%$ in nondiabetic mice; ${ }^{a} \mathrm{p}=0.04$ ) are shown in injured (a) and uninjured mice (b).

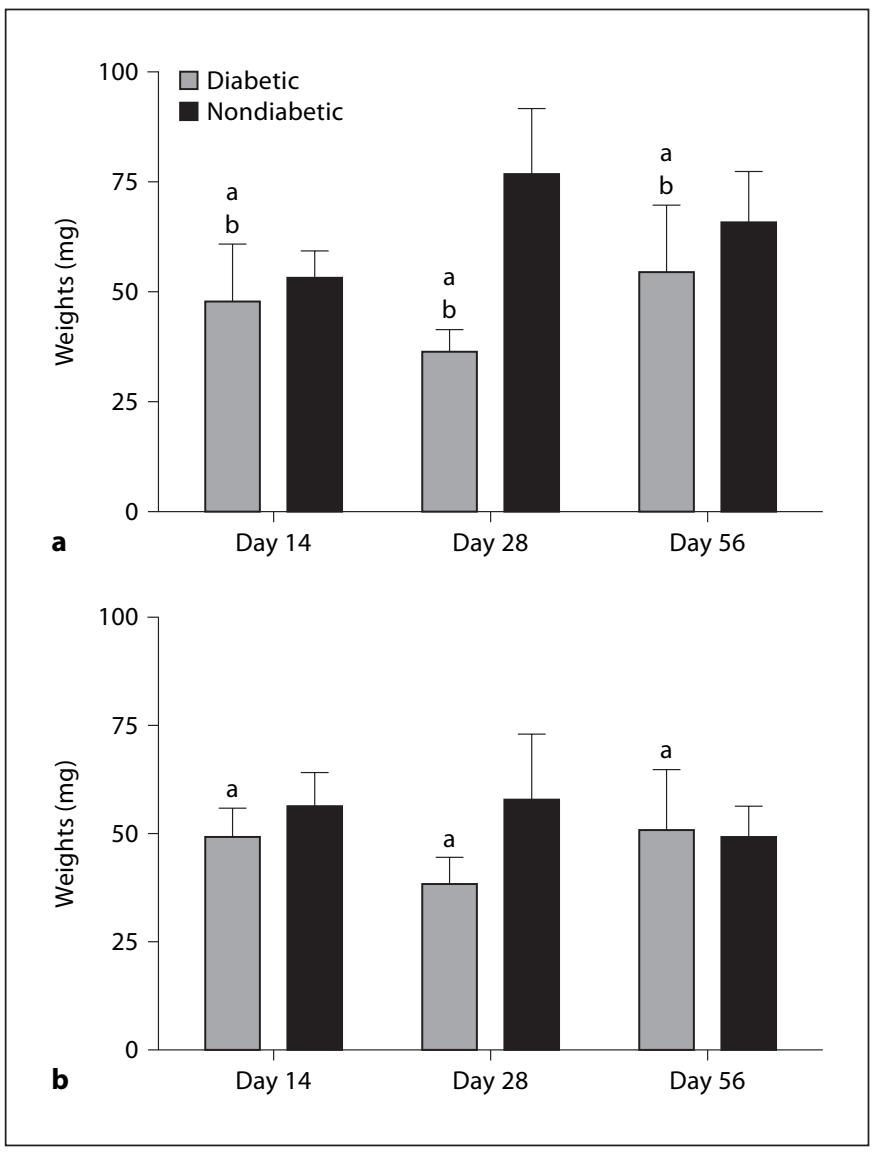

Fig. 6. Weights of TA muscles after myotoxic injury in Akita mice (means \pm SEM; $\mathrm{n}=4-6 /$ group). Main significant effects of diabetes $(45.4 \pm 1.0$ in diabetic vs. $60.8 \pm 2.0 \mathrm{mg}$ in nondiabetic mice; ${ }^{\mathrm{a}} \mathrm{p}=0.0001$ ) and diabetes-myotoxic injury interaction (nondiabetic mice: $65.5 \pm 2.2$ in myotoxic-treated muscles vs. $56.2 \pm$ $3.0 \mathrm{mg}$ in myotoxic-untreated muscles; ${ }^{\mathrm{b}} \mathrm{p}=0.008$ ) are shown in injured (a) and uninjured mice (b).

sponse to nerve stimulation of regenerating muscles. We found this same detrimental effect of diabetes in the case of the uninjured muscles, which is in agreement with previous studies $[2,12]$. It is very likely that the reduction in regenerating muscle weights is the cause of the maximal force deficit since specific maximal force was not decreased by diabetes.

It has been documented that insulin deficiency may cause atrophy of uninjured muscles due to increased muscle protein degradation and decreased protein synthesis [22]. The FoxO family of transcription factors promote the expression of atrogenes that are necessary for rapid muscle atrophy via the increase in protein degradation by the ubiquitin proteasome pathway $[5,6]$. Interestingly, we found that the levels of the transcripts for atro- 


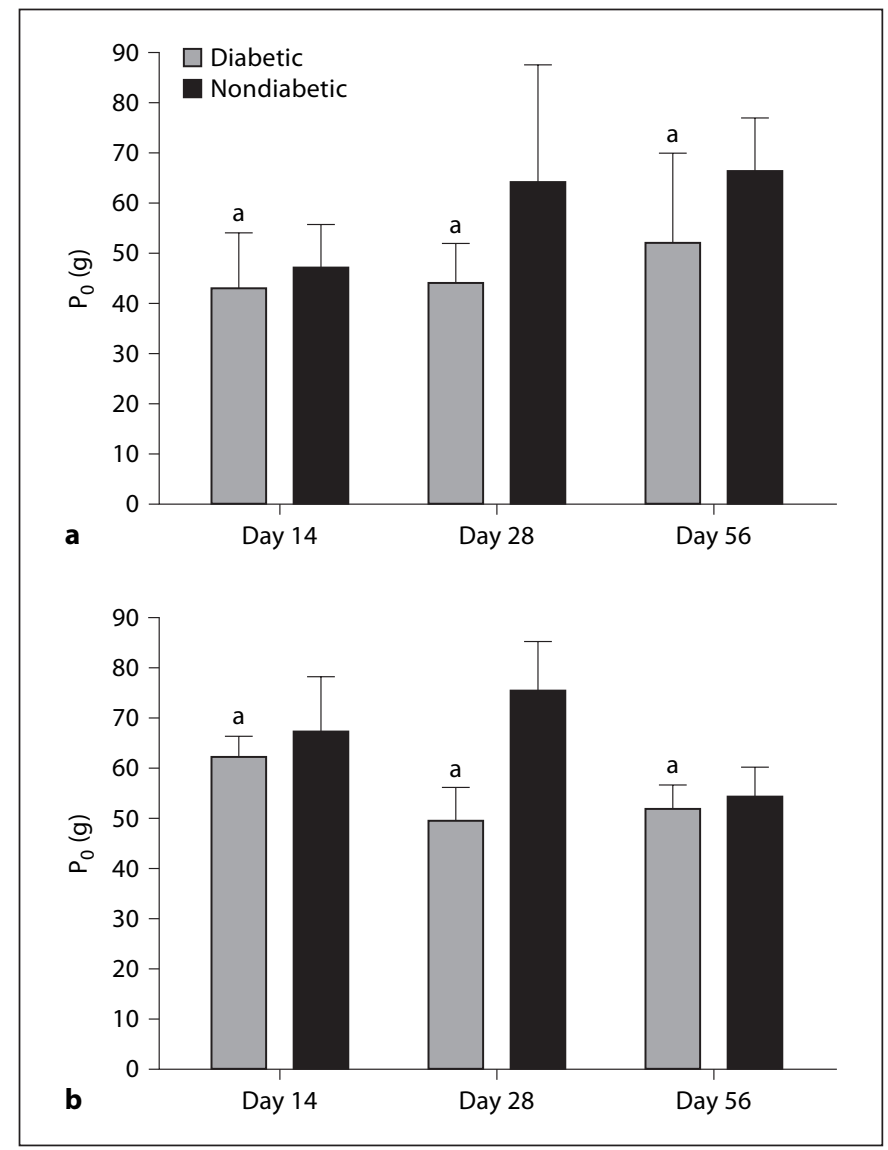

Fig. 7. Maximal tetanic force $\left(\mathrm{P}_{0}\right)$ of TA muscles after myotoxic injury in Akita mice (means \pm SEM; $n=4-6$ /group). Main significant effects of diabetes $(49.4 \pm 3.3$ in diabetic vs. $61.5 \pm$ $3.3 \mathrm{~g}$ in nondiabetic mice; ${ }^{\mathrm{a}} \mathrm{p}=0.0008$ ) are shown in injured (a) and uninjured mice (b).

gin-1, MuRF1 and FoxO3A were not upregulated either by STZ-induced or Akita diabetes 3 months after the onset. Therefore, it is not possible to explain the more marked effect of chemically induced diabetes versus genetic diabetes on muscle weight by an increased expression of atrogenes in diabetic STZ-treated mice compared to diabetic Akita mice. The return to the basal levels of the MuRF1 and Atrogin-1 indicates that the maintenance of the atrophic state in the diabetic environment for 3 months was no longer under the control of these two atrogenes. These results strongly suggest that atrogene activation is a transient event during diabetes, which is in line with a very recent study showing that induction of many atrogenes ended 14 days after the induction of muscle wasting by denervation, concomitantly with the end of the phase of rapid muscle mass loss [23]. It will, though,

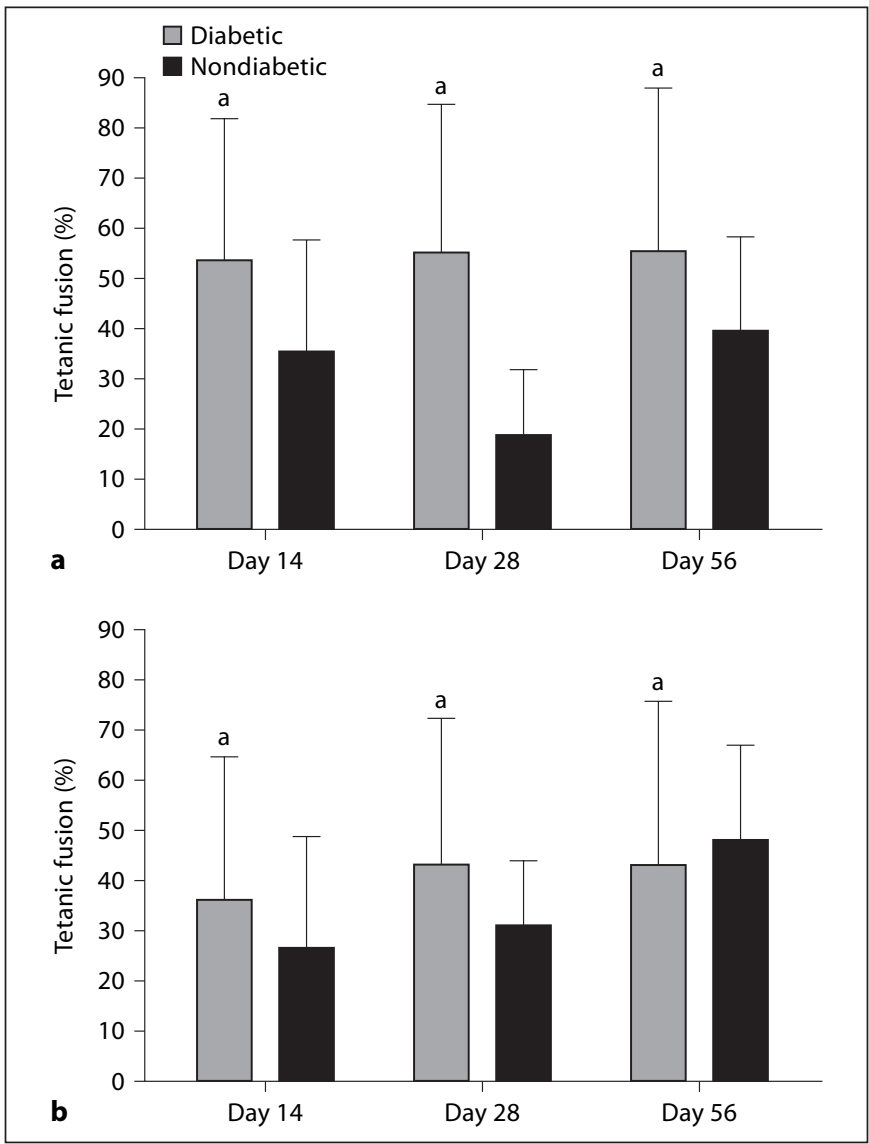

Fig. 8. Tetanic fusion of TA muscles after myotoxic injury in Akita mice (means $\pm S E M ; n=4-6 /$ group). Main significant effects of diabetes $(47.8 \pm 3.7$ in diabetic vs. $33.2 \pm 2.6 \%$ in nondiabetic mice; ${ }^{\mathrm{a}} \mathrm{p}=0.003$ ) are shown in injured (a) and uninjured mice (b).

be very interesting to identify the mechanisms responsible for the maintenance of long-term muscle atrophy in diabetic muscles. It still appears possible that the difference in muscle weights measured between the two diabetes models is a secondary consequence of a greater muscle atrophy that would have happened in STZ-treated as compared to Akita mice during the first few weeks following diabetes onset and before the expression of the atrogenes returned to a basal level. This question could be addressed by quantifying Atrogin- 1 and MurF1 transcript levels at different times after the onset of diabetes. Diabetes has also been reported to reduce the expression in satellite cells of myogenic regulatory factors that control muscle growth and regeneration [24]. NO dysregulation induced by diabetes [25] could also lead to deficient muscle growth and regeneration since $\mathrm{NO}$ is involved in 


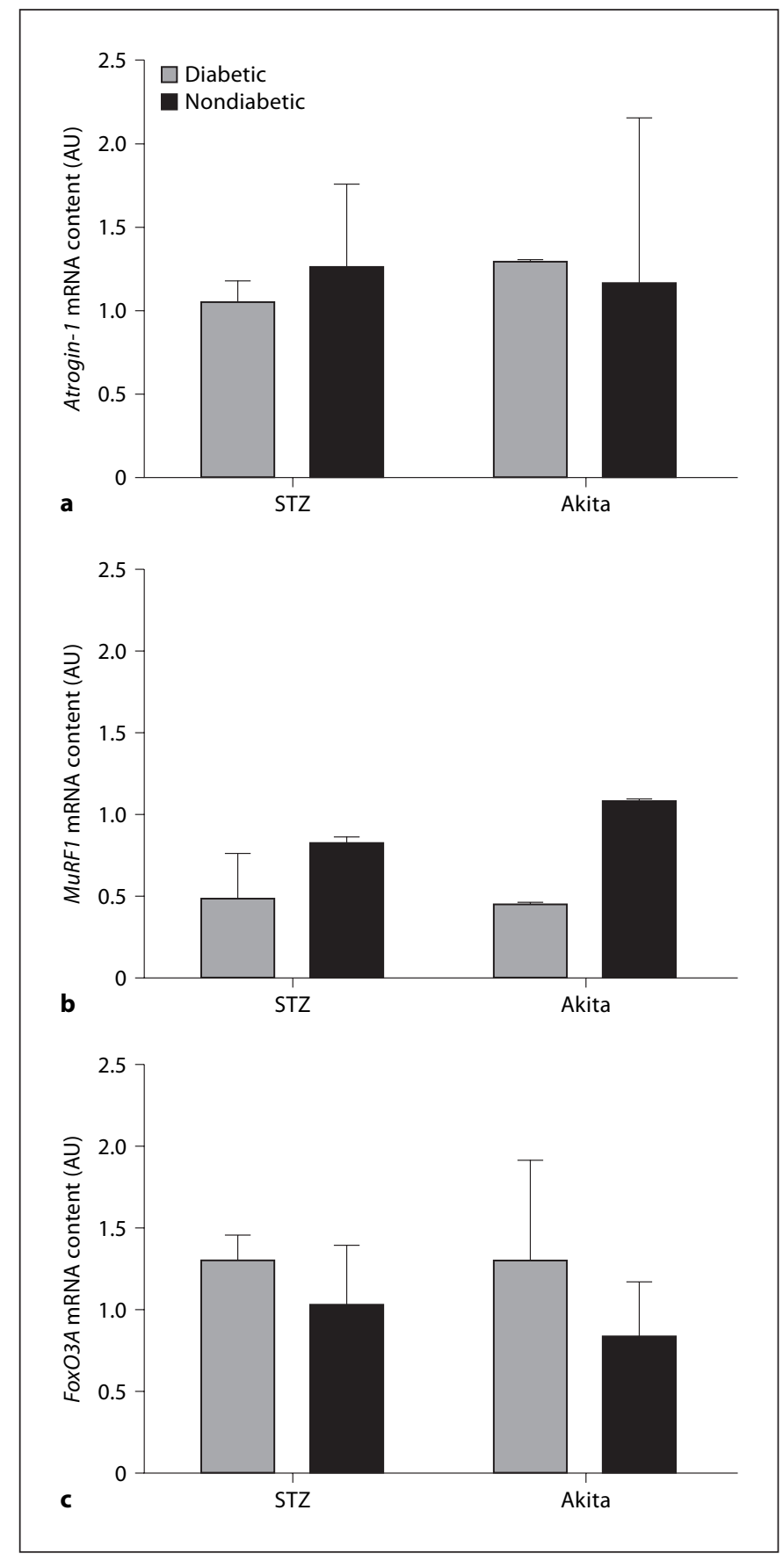

Fig. 9. Relative expression levels of atrogenes in TA muscles. Atrogin-1 (a), FoxO3 (b) and MuRF1 (c) mRNA contents in myotoxicuntreated muscles were measured 2 months after injury in STZtreated mice and Akita mice (means \pm SEM). AU = Arbitrary units.
Table 1. Effects of diabetes (\%, compared to nondiabetic): comparison between STZ-treated Swiss mice and Akita mice

\begin{tabular}{|c|c|c|}
\hline & STZ-treated mice & Akita mice \\
\hline Weight, mg & $-55.9 \pm 22.4^{\mathrm{a}, \mathrm{b}}$ & $-26.6 \pm 6.8^{\mathrm{a}}$ \\
\hline Tetanic fusion, $\%$ & $160.1 \pm 45.5^{\mathrm{a}, \mathrm{b}}$ & $51.0 \pm 26.7^{\mathrm{a}}$ \\
\hline Maximal tetanic force, $\mathrm{g}$ & $-46.8 \pm 18.8^{\mathrm{a}, \mathrm{b}}$ & $-24.5 \pm 3.2^{\mathrm{a}}$ \\
\hline Specific maximal tetanic & & \\
\hline force, $\mathrm{g} / \mathrm{g}$ & $30.1 \pm 10.3^{\mathrm{a}, \mathrm{b}}$ & $5.6 \pm 1.2$ \\
\hline Fatigue resistance, $\mathrm{s}$ & $-25.6 \pm 7.1^{\mathrm{a}}$ & $-15.7 \pm 5.3$ \\
\hline
\end{tabular}

satellite cell activation [26]. Another explanation of the detrimental effects of diabetes on muscle size may be a decrease in the blood supply to muscles [27] and a deficient neurotransmission [2]. Indeed, efficient muscle vascularization and innervation are known to be essential for muscle maintenance and regeneration [18].

Moreover, both STZ-induced diabetes in Swiss mice and diabetes of genetic origin in Akita mice increased the degree of tetanic fusion of regenerating muscles as well as in uninjured muscles. These results are in agreement with previous observations showing that diabetes modifies the processes of excitation-contraction-relaxation in uninjured diabetic muscles $[28,29]$. We did not exactly determine how the diabetic state alters the muscle function. However, it has been suggested that hyperglycemia is responsible for the change in muscle contractility, at least in uninjured muscles [29]. Hyperglycemia induces the production of oxygen free radicals and dysregulation of NO [25]. It has been well established that increases in reactive oxygen species and $\mathrm{NO}$ lead to contractile dysfunction in muscles [30]. Another explanation might be that posttranslational modifications of proteins, such as glycosylation of muscle contractile proteins due to hyperglycemia could modify muscle function, as demonstrated for glucose exposure [31]. Moreover, another possibility is that a change in muscle phenotype (fast/slow) has occurred. It is interesting to note that a high degree of tetanic fusion is characteristic of slow muscles and correlates with slow myosin heavy chain expression [32]. In addition, it has been reported that diabetes induces a fast/slow myosin shift in fast muscles [33] that was not associated with an increased fatigue resistance $[2,3]$. 
Taken together, our findings indicate for the first time that the diabetic state provides an unfavorable environment for maintenance of muscle mass and restoration of neuromuscular function after injury. This conclusion is in line with the few studies that have previously examined tissue healing in diabetic animals [9, 10, 13]. Gulati and Swamy [9] reported that diabetes reduces muscle mass and myofiber size after muscle transplantation. Further evidence for the role of normal insulin and glucose levels in skeletal muscle is that diabetic muscles regenerate better with respect to both muscle weight and myofiber size when transplanted into nondiabetic as compared to diabetic hosts [9]. In the context of many previous reports, our data lead to the conclusion that the presence of insulin together with male sexual steroids and thyroid hormones $[34,35]$ are necessary to create a favorable environment for the formation of new muscle fibers and recovery of neuromuscular function after myotoxic injury.

\section{Conclusion}

The present study demonstrates that diabetes induces detrimental effects on both normal and regenerating muscles in mice. Regenerating fast muscles are weaker, lighter and functionally slower in diabetic mice than in nondiabetic mice. These results should encourage us to search for new treatments able to increase muscle mass and improve neuromuscular function in the diabetic environment. Impaired recovery after muscle injury could explain, at least in part, the muscle atrophy and weakness which is observed in diabetic patients.

\section{Acknowledgments}

We express our thanks for the contribution and support of I. Martelly (CNRS UMR 7149, Créteil, France), L. Schaeffer (CNRS UMR 5239, Lyon, France), Universities Paris 5, 6 and 12, INSERM and the Association Française contre les Myopathies. We are grateful to R. Comte for his technical assistance.

\section{References}

- 1 Cotter MA, Cameron NE, Robertson S, Ewing I: Polyol pathway-related skeletal muscle contractile and morphological abnormalities in diabetic rats. Exp Physiol 1993;78: 139-155.

2 Fahim MA, el-Sabban F, Davidson N: Muscle contractility decrement and correlated morphology during the pathogenesis of streptozotocin-diabetic mice. Anat Rec 1998;251:240-244.

3 McGuire M, MacDermott M: The influence of streptozotocin diabetes and metformin on erythrocyte volume and on the membrane potential and the contractile characteristics of the extensor digitorum longus and soleus muscles in rats. Exp Physiol 1999;84:10511058.

4 Sanchez OA, Snow LM, Lowe DA, Serfass RC, Thompson LV: Effects of endurance exercise-training on single-fiber contractile properties of insulin-treated streptozotocininduced diabetic rats. J Appl Physiol 2005; 99:472-478.

5 Price SR, Bailey JL, Wang X, Jurkovitz C, England BK, Ding X, Phillips LS, Mitch WE: Muscle wasting in insulinopenic rats results from activation of the ATP-dependent, ubiquitin-proteasome proteolytic pathway by a mechanism including gene transcription. J Clin Invest 1996;98:1703-1708.

6 Lecker SH, Jagoe RT, Gilbert A, Gomes M, Baracos V, Bailey J, Price SR, Mitch WE, Goldberg AL: Multiple types of skeletal muscle atrophy involve a common program of changes in gene expression. FASEB J 2004; 18:39-51.
7 Plaghki L: Regeneration and myogenesis of striated muscle (in French). J Physiol (Paris) 1985;80:51-110.

-8 Harris JB: Myotoxic phospholipases A2 and the regeneration of skeletal muscles. Toxicon 2003;42:933-945.

-9 Gulati AK, Swamy MS: Regeneration of skeletal muscle in streptozotocin-induced diabetic rats. Anat Rec 1991;229:298-304.

10 Talesara CL, Vashishta N: Regenerative ability of gastrocnemius muscle under diabetic condition with special reference to SDH \& m-ATPase. Indian J Exp Biol 2000;38:567574.

11 Faulkner JA, Cote C: Functional deficits in skeletal muscle grafts. Fed Proc 1986;45: 1466-1469.

12 Lesniewski LA, Miller TA, Armstrong RB: Mechanisms of force loss in diabetic mouse skeletal muscle. Muscle Nerve 2003;28:493500.

13 Chbinou N, Frenette J: Insulin-dependent diabetes impairs the inflammatory response and delays angiogenesis following Achilles tendon injury. Am J Physiol Regul Integr Comp Physiol 2004;286:R952-R957.

14 Gonzalez C, Cuvellier S, Hue-Beauvais C, Levi-Strauss M: Genetic control of non obese diabetic mice susceptibility to high-dose streptozotocin-induced diabetes. Diabetologia 2003;46:1291-1295.
15 Yoshioka M, Kayo T, Ikeda T, Koizumi A: A novel locus, Mody4, distal to D7Mit189 on chromosome 7 determines early-onset NIDDM in nonobese C57BL/6 (Akita) mutant mice. Diabetes 1997;46:887-894.

16 Couteaux R, Mira JC, d'Albis A: Regeneration of muscles after cardiotoxin injury. I. Cytological aspects. Biol Cell 1988;62:171182.

17 Vignaud A, Cebrian J, Martelly I, Caruelle JP, Ferry A: Effect of anti-inflammatory and antioxidant drugs on the long-term repair of severely injured mouse skeletal muscle. Exp Physiol 2005;90:487-495.

18 Hourde C, Vignaud A, Beurdy I, Martelly I, Keller A, Ferry A: Sustained peripheral arterial insufficiency durably impairs normal and regenerating skeletal muscle function. J Physiol Sci 2006;56:361-367.

19 Gallo M, Gordon T, Tyreman N, Shu Y, Putman CT: Reliability of isolated isometric function measures in rat muscles composed of different fibre types. Exp Physiol 2004;89: 583-592.

20 Wold LE, Ren J: Streptozotocin directly impairs cardiac contractile function in isolated ventricular myocytes via a p38 map kinasedependent oxidative stress mechanism. Biochem Biophys Res Commun 2004;318:10661071 .

21 Wang J, Takeuchi T, Tanaka S, Kubo SK, Kayo T, Lu D, Takata K, Koizumi A, Izumi T: A mutation in the insulin 2 gene induces diabetes with severe pancreatic beta-cell dysfunction in the Mody mouse. J Clin Invest 1999;103:27-37. 
-22 Chow LS, Albright RC, Bigelow ML, Toffolo G, Cobelli C, Nair KS: Mechanism of insulin's anabolic effect on muscle - measurements of muscle protein synthesis and breakdown using aminoacyl tRNA and other surrogate measures. Am J Physiol Endocrinol Metab 2006;291:E729-E736.

23 Sacheck JM, Hyatt JP, Raffaello A, Jagoe RT, Roy RR, Edgerton VR, Lecker SH, Goldberg AL: Rapid disuse and denervation atrophy involve transcriptional changes similar to those of muscle wasting during systemic diseases. FASEB J 2007;21:140-155.

-24 Aragno M, Mastrocola R, Catalano MG, Brignardello E, Danni O, Boccuzzi G: Oxidative stress impairs skeletal muscle repair in diabetic rats. Diabetes 2004;53:1082-1088.

25 Droge W: Free radicals in the physiological control of cell function. Physiol Rev 2002;82: 47-95.
26 Wozniak AC, Kong J, Bock E, Pilipowicz O, Anderson JE: Signaling satellite-cell activation in skeletal muscle: markers, models, stretch, and potential alternate pathways. Muscle Nerve 2005;31:283-300.

27 Schalkwijk CG, Stehouwer CD: Vascular complications in diabetes mellitus: the role of endothelial dysfunction. Clin Sci (Lond) 2005;109:143-159.

28 Malhotra A, Sanghi V: Regulation of contractile proteins in diabetic heart. Cardiovasc Res 1997;34:34-40.

29 Davidoff AJ: Convergence of glucose- and fatty acid-induced abnormal myocardial excitation-contraction coupling and insulin signalling. Clin Exp Pharmacol Physiol 2006;33:152-158.

30 Smith MA, Reid MB: Redox modulation of contractile function in respiratory and limb skeletal muscle. Respir Physiol Neurobiol 2006;151:229-241.

$>31$ Ramamurthy B, Hook P, Jones AD, Larsson $\mathrm{L}$ : Changes in myosin structure and function in response to glycation. FASEB J 2001;15: 2415-2422.
2 Gerrits HL, Hopman MT, Offringa C, Engelen BG, Sargeant AJ, Jones DA, Haan A: Variability in fibre properties in paralysed human quadriceps muscles and effects of training. Pflugers Arch 2003;445:734-740.

33 Fewell JG, Moerland TS: Responses of mouse fast and slow skeletal muscle to streptozotocin diabetes: myosin isoenzymes and phosphorous metabolites. Mol Cell Biochem 1995; 148:147-154.

34 d'Albis A, Weinman J, Mira JC, Janmot C, Couteaux R: The regulator role of thyroid hormones in myogenesis. Analysis of isoforms of myosin in muscular regeneration (in French). CR Acad Sci III 1987;305:697702 .

-35 Ferry A, Noirez P, Page CL, Salah IB, Daegelen D, Rieu M: Effects of anabolic/androgenic steroids on regenerating skeletal muscles in the rat. Acta Physiol Scand 1999;166: 105-110. 